University of Nebraska - Lincoln

DigitalCommons@University of Nebraska - Lincoln

Michigan Bovine Tuberculosis Bibliography and

Database

Wildlife Disease and Zoonotics

2009

\title{
Spatial Ecology of Raccoons Related to Cattle and Bovine Tuberculosis in Northeastern Michigan
}

\author{
Todd Atwood \\ USDA/APHIS/WS National Wildlife Research Center \\ Thomas Deliberto \\ USDA/APHIS/WS National Wildlife Research Center, Thomas.J.DeLibertot@aphis.usda.gov \\ Holly Smith \\ USDA/APHIS/WS National Wildlife Research Center \\ Justin Stevenson \\ USDA/APHIS/WS National Wildlife Research Center
}

Kurt C. VerCauteren

USDA/APHIS/WS National Wildlife Research Center, kurt.c.vercauteren@usda.gov

Follow this and additional works at: https://digitalcommons.unl.edu/michbovinetb

Part of the Veterinary Medicine Commons

Atwood, Todd; Deliberto, Thomas; Smith, Holly; Stevenson, Justin; and VerCauteren, Kurt C., "Spatial Ecology of Raccoons Related to Cattle and Bovine Tuberculosis in Northeastern Michigan" (2009).

Michigan Bovine Tuberculosis Bibliography and Database. 4.

https://digitalcommons.unl.edu/michbovinetb/4

This Article is brought to you for free and open access by the Wildlife Disease and Zoonotics at DigitalCommons@University of Nebraska - Lincoln. It has been accepted for inclusion in Michigan Bovine Tuberculosis Bibliography and Database by an authorized administrator of DigitalCommons@University of Nebraska - Lincoln. 


\title{
Spatial Ecology of Raccoons Related to Cattle and Bovine Tuberculosis in Northeastern Michigan
}

TODD C. ATWOOD, ${ }^{1}$ United States Department of Agriculture/Animal and Plant Health Inspection Service/Wildlife Services/National Wildlife Research Center, 4101 LaPorte Avenue, Fort Collins, CO 80521, USA

THOMAS J. DELIBERTO, United States Department of Agriculture/Animal and Plant Health Inspection Service/Wildlife Services/National Wildlife Research Center, 4101 LaPorte Avenue, Fort Collins, CO 80521, USA

HOLLY J. SMITH, United States Department of Agriculture/Animal and Plant Health Inspection Service/Wildlife Services/National Wildlife Research Center, 4101 LaPorte Avenue, Fort Collins, CO 80521, USA

JUSTIN S. STEVENSON, United States Department of Agriculture/Animal and Plant Health Inspection Service/Wildlife Services/National Wildlife Research Center, 4101 LaPorte Avenue, Fort Collins, CO 80521, USA

KURT C. VERCAUTEREN, United States Department of Agriculture/Animal and Plant Health Inspection Service/Wildlife Services/National Wildlife Research Center, 4101 LaPorte Avenue, Fort Collins, CO 80521, USA

\begin{abstract}
In 1995, Mycobacterium bovis, the causative bacterium of bovine tuberculosis (bTB), was detected in 5 beef cattle operations in Alcona County, Michigan, USA. In accordance with Federal law, the operations were depopulated to prevent the spread of bTB. Subsequent wildlife surveillance programs identified high prevalence of M. bovis in mesocarnivores, including raccoons (Procyon lotor), which suggested that raccoons may be complicit in vectoring the pathogen among livestock operations. Our goal was to develop an empirical basis for generating hypotheses about the likelihood for raccoons to mediate the transmission of bTB to livestock. We found intersexual differences in scaledependent resource selection and probability of spatial interaction that, under certain circumstances, may form the foundation for a sex-bias in disease transmission. Spatial dispersion of mixed-forest patches facilitated overlap of adjacent males, whereas female overlap zones included pastures. Within overlap zones, probabilities of interaction for male-male and male-female dyads were greater than for female-female dyads, although we documented an elevated likelihood of spatial interaction between raccoons and livestock around cattle-feeding troughs and water sources, regardless of sex. Partial regressions generated by linear models indicated that distance between nearest-neighbor mixed-forest patches explained most of this observed variation. These results supported our prediction that forest patches juxtaposed with anthropogenic features fostered social tolerance between males and, thus, facilitated spatial interaction and exploitation of anthropogenic features. In raccoons, sex and landscape composition influenced pathogen transmission potential. We suggest that livestock producers locate livestock feeding and watering features away from forest patches to mitigate future outbreaks of bTB in endemic areas. (JOURNAL OF WILDLIFE MANAGEMENT 73(5):647-654; 2009)
\end{abstract}

DOI: $10.2193 / 2008-215$

KEY WORDS bovine tuberculosis, disease, Michigan, Mycobacterium bovis, Procyon lotor, raccoon, resource selection, sexinfluenced, spatial epidemiology.

Most domestic animal pathogens can infect $>1$ wildlife host species (Cleaveland et al. 2001, Taylor et al. 2001), and nearly $50 \%$ of emerging (e.g., severe acute respiratory syndrome [SARS], human immunodeficiency virus [HIV]) or reemerging (e.g., tuberculosis, West Nile virus, malaria) pathogens found to affect humans have a wildlife reservoir (Dobson and Foufopoulos 2001, Woolhouse and GowtageSequeria 2005). The spatial epidemiologies of several infectious zoonoses (e.g., SARS, HIV, avian influenza) appear to be strongly influenced by anthropogenic activities, including intensive agriculture (Schrag and Wiener 1995), and habitat fragmentation (McCallum and Dobson 2002). Thus, a better understanding of the interaction of disease dynamics between domestic and free-ranging animals is warranted.

The risk associated with reservoirs of wildlife diseases has recently increased because of environmental alteration and farming of nondomestic ruminants (Blancou et al. 2005). Concomitantly, media reports of wildlife disease outbreaks have increased public concern regarding the role of wildlife in spreading diseases (Taylor et al. 2001). In the scientific community, these concerns have resulted in renewed interest

${ }^{1}$ E-mail: todd.c.atwood@aphis.usda.gov in development of protocols to proactively manage the risk of disease transmission.

Wildlife diseases often emerge from complex ecological communities involving several potential hosts interacting over multiple spatial scales. Although perturbations resulting from human alteration of landscapes have been wellexplicated (Weins et al. 1986, Turner 1989, Crooks and Soule 1999, Theobald 2003), less effort has been devoted to elucidating the nexus between behavior, landscape attributes, and transmission of disease.

Juxtaposition of critical resource patches (e.g., protective cover, foraging habitat) relative to centers of anthropogenic activity elevates the probability of interactions between wildlife, domestic animals, and humans (Smith et al. 2002, Beasley et al. 2007). Aggregation of food resources can facilitate relaxation of behaviorally mediated individual spacing patterns resulting in high spatial overlap and interaction of otherwise territorial individuals (Macdonald et al. 1999, Atwood and Weeks 2003, Atwood et al. 2007). Not surprisingly, where probabilities of interaction are elevated, disease prevalence often is correspondingly high (Rhodes et al. 1998, Tuyttens et al. 2000), which may be particularly true for human-altered habitats centered on livestock production, where forage production and animal 
husbandry operations may be focal attractors for wildlife (Isbell et al. 1998, Wilmhurst et al. 1999).

Prange et al. (2004) postulated that spacing patterns and resource selection of facultatively solitary carnivores should be most sensitive to effects of food aggregation. In particular, spatial distribution of females should be highly correlated with distribution of food resources because reproductive success is closely related to the ability to efficiently exploit food patches (Prange et al. 2004). Areas characterized by anthropogenically aggregated food patches are likely focal attractors for solitary females, resulting in artificially high densities and extensive spatial overlap. When free-ranging animals share space and food resources with domestic livestock, the potential for cross-species disease transmission can be elevated.

Raccoons (Procyon lotor) are largely solitary (though see Gehrt and Fritzell 1998), nonterritorial carnivores ubiquitous in agrarian landscapes (Prange et al. 2004). Raccoons also are recognized as primary and spill-over hosts for several zoonoses that represent health threats to humans and domestic animals (e.g., Broadfoot et al. 2001, Roussere et al. 2002). Thus raccoons are an appropriate species for examining the interaction between behavior, landscape attributes, and disease transmission.

Few studies have been published relating the juxtaposition of critical resource patches and resource selection with the spatial epidemiology of wildlife diseases (Mollison and Levin 1995, Hess et al. 2002, Smith et al. 2002, Conner and Miller 2004) and no studies have been published on these effects in relation to wildlife-livestock interactions. We developed and evaluated an empirical basis for generating hypotheses about the potential role of raccoon-mediated transmission of Mycobacterium bovis, the causative agent of bovine tuberculosis (bTB), typically acquired through inhalation of aerosolized bacilli or ingestion of infected material (Francis 1958). Our objective was to assess the extent to which raccoons exploit space used by livestock to better understand the potential for disease transmission between free-ranging wildlife and domestic animals. Specifically, we examined 1) general spatial ecology of raccoons at the wildlife-livestock-human interface, 2) the potential for interaction between raccoons and livestock, and 3) the potential for behavior and landscape attributes to modulate horizontal disease transmission by wildlife to livestock.

\section{STUDY AREA}

We conducted our research in a $293-\mathrm{km}^{2}$ area, encompassing 4 adjacent beef cattle operations in Alcona County, Michigan, USA. In 1995, M. bovis was found to be endemic in free-ranging white-tailed deer (Odocoileus virginianus) in a 4-county area that included our study site (Schmitt et al. 1997). Subsequent to discovery of a wildlife reservoir for bTB, a multispecies surveillance program conducted by the Michigan Department of Natural Resources identified raccoons as a spill-over host for $M$. bovis. In 2004, apparent prevalence of bTB within the 4-county endemic area was $1.7 \%$ for white-tailed deer (Michigan Department of
Natural Resources 2005), 33\% for coyotes (Canis latrans; K. C. VerCauteren, National Wildlife Research Center, unpublished data), and $2.4 \%$ for raccoons (Berentsen et al. 2007). From 1996 to 2003, 23 cattle from 5 herds in Alcona County were confirmed to be $\mathrm{bTB}+$, and the herds were depopulated.

The 4 cattle properties $(\bar{x}=131$ ha, range $=105-161$ ha $)$ within the study area were cow and calf operations with an average herd size of 72 (range $=50-104)$ animals and an average stocking rate of $0.64 \mathrm{animal} / \mathrm{ha}$. Following spring calving, cattle were systematically rotated through 2-3 pastures for the summer. Loafing sheds, containing feed troughs where cattle were occasionally fed corn and supplemental minerals, were located within pastures as were water tanks or natural water sources. Raccoons were ubiquitous throughout the study area.

The greater study area was physiographically diverse, with uplands dominated by row-crop agriculture (corn and soybean) and pastures. Forests of jack pine (Pinus banksiana), white pine (Pinus alba), oak (Quercus spp.), and maple (Acer spp.) were present in undisturbed uplands. Wetland ephemera were common in lowlands, where dominant vegetation was tag alder (Alnus rugosa) and white cedar (Thuja occidentalis). Mixed forest (conifer and deciduous), pasture, corn fields, conifer forests, wetlands, anthropogenic features (e.g., houses, barns, grain-storage facilities), and deciduous forest comprised $53 \%, 32 \%, 9 \%$, $5 \%, 1 \%$, and $0.3 \%$, respectively. Annual precipitation typically ranged from $71 \mathrm{~cm}$ to $91 \mathrm{~cm}$, the bulk of which occurred as snowfall. Mean yearly summer and winters temperatures were $21^{\circ} \mathrm{C}$ and $-10^{\circ} \mathrm{C}$, respectively.

\section{METHODS}

We captured raccoons using padded foot-hold and box traps from 19 April to 16 June 2004. We immobilized raccoons with an intramuscular injection of ketamine hydrochloride and xylazine (ketamine: $10 \mathrm{mg} / \mathrm{kg}$; xylazine $0.08 \mathrm{mg} / \mathrm{kg}$ ), collected morphometric data, and attached ear tags and radiocollars (Advanced Telemetry Systems, Isanti, MN). We extracted a premolar from each raccoon for cementum annuli determination of age (Matson's Laboratory, LLC, Milltown, MT) and administered yohimbine $(0.125 \mathrm{mg} / \mathrm{kg})$ as an immobilant antagonist. Additionally, we equipped 9 cows on 2 farms with ear-tag transmitters (Wildlife Track, Inc., Livermore, CA). We located radiocollared raccoons and cows using portable receivers (Advanced Telemetry Systems) and handheld 4-element antennas. Research and handling protocols (QA-1147) were reviewed and approved by the Institutional Animal Care and Use Committee at the National Wildlife Research Center.

We structured our telemetry sampling design so that we collected $\geq 3$ locations per individual per week over a nocturnal interval partitioned into 3 periods $(1900-2300 \mathrm{hr}$, 2300-0300 hr, 0300-0700 hr). We obtained one location per individual within a 3-period interval (i.e., 1900-0700 hr) so that consecutive locations were separated by $\geq 12$ hours to guard against spatial autocorrelation (Swihart and Slade 
1997). Thus, within a week, we collected $\geq 3$ locations from 3 separate time periods for each raccoon. We converted differentially corrected triangulation data to point locations using the maximum likelihood estimator computed by the software Locate II (Nams 1990). We calculated true bearings for a set of reference transmitters following White and Garrott (1990) and used the standard deviation between bearings (Lee et al. 1985) to calculate 95\% confidence ellipses. Because we needed fine-resolution data for spatial analyses, we censored bearings from data collected over $>10$ minutes and having an error ellipse $\geq 0.50$ ha. We determined home-range $(95 \%$ utilization distribution [UD]) and core-area (50\% UD; Chamberlain et al. 2002) sizes using the fixed-kernel (FK) option in the Animal Movement extension in ArcView 3.2. Fixed-kernel estimators allow identification of disjunct areas of activity (Seaman et al. 1999), a particularly important consideration in anthropogenically disturbed landscapes.

We conducted weekly radiotelemetry homing sessions during diurnal periods to identify raccoon loafing and denning sites. Each week we tracked 3-5 individuals to daytime bedding areas where we recorded habitat characteristics and location to identify sites located within the agrolivestock complex. In addition to ground-based telemetry, we used data loggers and animal-activated infrared digital cameras (Reconyx, LaCrosse, WI) to further investigate the potential for inter- and intraspecific contact at anthropogenic food and water sources. We collected presence data for raccoons and cattle at 3 artificial water sources (i.e., water impoundments and stock tanks) on 2 farms using data loggers and receivers. Data loggers collected presence and absence data by cycling through all available frequencies every 3-5 minutes. During June-August, we placed 6 infrared digital cameras (i.e., 2-3 cameras/property) $\leq 10 \mathrm{~m}$ from water sources where we suspected probability of intraand interspecific interaction was high. We programmed cameras to operate 24 hours/day and to take 99 images over a 2-minute period upon activation with no lag between subsequent activations. Time, date, and temperature were recorded on each image. We stored images on 512megabyte compact flash cards capable of storing 12,000 images and replaced flash cards and batteries bi-weekly. We defined a contact event as a camera activation in which a radiotagged animal (raccoon or cow) made naso-oral contact with feature contents (i.e., water). If $>5$ minutes lapsed between sequential activations, we considered them independent unless the same animal initiated both activations. We analyzed whether duration (i.e., time between first and last contact) of water-source use differed between raccoons and cattle using a Kruskal-Wallis test (Zar 1999).

\section{Spatial Analysis}

We quantified spatial overlap of summer home ranges $(95 \%$ FK) of raccoons using theme-overlay routines in ArcView. We calculated percent overlap as

$$
\begin{aligned}
\text { overlap }= & {\left[\left(\operatorname{area}_{\alpha \beta} / \text { home range } \alpha\right)\right.} \\
& \left.\times\left(\operatorname{area}_{\alpha \beta} / \text { home } \text { range }_{\beta}\right)\right]^{0.5}
\end{aligned}
$$

where area $a_{\alpha \beta}$ was the overlap area common to home ranges $\alpha$ and $\beta$, and home range $\alpha$ and home range $\beta$ were the respective individual home ranges. We quantified distribution of locations relative to habitat type within home ranges, core areas, and overlap zones $(\mathrm{OZ}$; i.e., overlap area common to home ranges $\alpha$ and $\beta$ ) and determined availability of habitat types on the landscape using the overlay routines. We classified raccoon dyads that spatially overlapped each other based on sex (M-F, M-M, F-F). We estimated a probability of interaction $\left(P_{i j}\right)$ for each spatially overlapping dyad sample unit using the following equation from Conner and Miller (2004):

$$
P_{i j}=\sum R_{i j k} / n_{i}
$$

where $R_{i j k}$ is an indicator variable that was one for each $k$ location of a raccoon from home range $i$ found within the home range of $j$ and a zero otherwise, and $n_{i}$ was total number of locations for all raccoons in home range $i$.

We used resource selection functions (RSF; Manly et al. 2002) to determine use versus availability of landscape attributes for home ranges, core areas, and $\mathrm{OZ}$ of raccoons. We took simple random samples of 45 total point locations from each raccoon with $>45$ point locations to ensure that approximately equal weight was given to each raccoon in the analysis (Sawyer et al. 2006). At each spatial scale (i.e., home range, core area, and $\mathrm{OZ}$ ), we then matched one independent animal point location (i.e., use) with 3 randomly chosen points to represent resource availability. We selected random points from within circular buffers centered on the preceding animal location with a radius equal to the $95 \%$ movement distance for that relocation interval ( $\geq 12 \mathrm{hr}$; Arthur et al. 1996, Johnson et al. 2006). We related resource use and availability to 7 categorical habitat variables (i.e., conifer, deciduous, mixed forest, wetland, corn field, pasture, anthropogenic) and 2 continuous variables (i.e., distance from road and water features in meters). We pooled data across individuals and estimated population-level resource selection functions via logistic regression using the following formula:

$$
\mathrm{W}^{*}=\exp \left(\beta_{1} \mathrm{X}_{1}+\beta_{2} \mathrm{X}_{2} \cdots+\beta_{p} \mathrm{X}_{p}\right)
$$

where $\mathrm{W}^{*}$ is an index of the relative probability of use of a given site and $\beta_{1-p}$ were the selection coefficients for resource variables $X_{1-p}$, respectively (Manly et al. 2002). In designs with used and available units, the true population sampling fraction is unknown and the resulting RSF is actually a relative probability because the intercept or $\beta_{0}$ coefficient is incorrectly scaled (Manly et al. 2002). Thus, following Manly et al. (2002) we dropped the intercept and denominator from the logistic form for this relative function. For all RSF models, we checked continuous variables for conformity to linearity using the quartile method (Hosmer and Lemeshow 2000). We ensured final model fit by testing with the Hosmer and Lemeshow goodness-of-fit statistic (Hosmer and Lemeshow 2000). We modeled categorical habitat variables using dummy-variable coding, excluding reference categories. 
We examined variation in home-range and core-area size using unbalanced factorial analysis of variance (Zar 1999) with sex as the main effect. We used mean squared differences (MSD) of nearest neighbor pasture, corn field, wetland, mixed, deciduous, and conifer forest patches, and pair type of overlapping raccoon dyads as independent variables in general linear models of probabilities of interaction ( $P_{i j}$, from eq 2$)$. We used dummy-variable coding for categorical variables (Neter et al. 1996). We assembled sets of candidate models based on habitat attributes retained in RSF models and identified in similar modeling efforts (Atwood and Weeks 2003). We assessed homoscedasticity of continuous variables using normal probability plots (Neter et al. 1996). We used Akaike's Information Criterion ( $\mathrm{AIC}_{c}$ for small sample sizes) to select the most parsimonious RSF and multiple-regression models (Burnham and Anderson 2002). We calculated Akaike weights $\left(w_{i}\right)$ to aid in determination of the best model; $w_{i}$ values approximate the probability that a model is the best Kullback-Leibler model (Burnham and Anderson 2002). When model uncertainty arose, we determined the relative likelihood that one model was better than another as $w_{i} / w_{j}$ (Burnham and Anderson 2002). We considered models with $\Delta_{i}$ values $>2.0$ (i.e., $\Delta_{i}=\mathrm{AIC}_{i}-\min$. AIC) to be significant (Burnham and Anderson 2002).

\section{RESULTS}

We radiotagged 67 raccoons (19 F, $48 \mathrm{M}), 50(13 \mathrm{~F}, 37 \mathrm{M})$ of which we monitored from capture to termination of our study. Radiotagged raccoons were distributed between the 4 cattle properties $(\bar{x}=16$ raccoons/property; range $=14-18$ raccoons/property), and humans were the primary cause of death; 9 were shot or trapped and 4 were killed by vehicles. We lost contact with an additional 4 raccoons when radiocollars malfunctioned. Killed and missing animals were distributed across the study area and did not appear to be the result of systematic eradication efforts. From May to September 2004, we collected 3,633 point locations (no. of locations/raccoon: $\bar{x}_{\text {male }}=74 ; \bar{x}_{\text {female }}=70$ ) for use in spatial analyses. We identified 57 den sites for 21 raccoons; $42(74 \%)$ dens were located within pastures concomitantly used by cattle, 8 dens $(14 \%)$ were located in tree cavities in mixed-forest patches, and 7 dens $(12 \%)$ were located in operational (e.g., silage or animal husbandry activities) or derelict (i.e., nonoperational) farm buildings. Nearly all dens $(95 \%)$ were located within $300 \mathrm{~m}(\bar{x}=261 \mathrm{~m}, \mathrm{SE}=7.6 \mathrm{~m})$ of a water source (artificial or natural). Although our study only spanned 5 months, it occurred during the period (spring and summer) when raccoons typically expand seasonal home-range size (Prange et al. 2004) and cattle exclusively occupy pastures. Thus intra- and interspecific contact should be more likely during this time period.

\section{Spatial Ecology}

Home-range and core-area sizes differed by sex (95\% FK: $F_{1,49}=4.75, P=0.03 ; 50 \%$ FK: $\left.F_{1,49}=4.73, P=0.03\right)$; male home ranges $\left(95 \% \mathrm{FK}: \bar{x}=1.89 \mathrm{~km}^{2}, 95 \% \mathrm{CI}=1.48-\right.$ 2.29) and core areas $\left(50 \% \mathrm{FK}: \bar{x}=0.42 \mathrm{~km}^{2}, 95 \% \mathrm{CI}=\right.$
$0.34-0.51)$ were larger than those of females (95\% FK: $\bar{x}=$ $1.25 \mathrm{~km}^{2}, 95 \% \mathrm{CI}=1.03-1.47 ; 50 \%$ FK: $\bar{x}=0.29 \mathrm{~km}^{2}$, $95 \% \mathrm{CI}=0.24-0.34)$. Home-range overlap occurred in 88 dyads, and the extent of overlap differed relative to dyad type $\left(F_{2,80}=4.12, P=0.04\right)$. Least-squares means testing indicated that extent of home-range overlap was similar between male-female $(n=18, \bar{x}=57 \%$ overlap, $\mathrm{SE}=2.6 \%$, $95 \% \mathrm{CI}=52-62 \%)$ and male-male dyads $(n=59, \bar{x}=39 \%$ overlap, $\mathrm{SE}=3.3 \%, 95 \% \mathrm{CI}=33-46 \%)$ but less for female-female dyads $(n=11, \bar{x}=23 \%$ overlap, $\mathrm{SE}=5.4 \%$, $95 \% \mathrm{CI}=12-34 \%)$. Extent of core-area overlap $(n=77$ overlapping dyads; $\bar{x}=9 \%$ overlap, $\mathrm{SE}=4.1 \%, 95 \% \mathrm{CI}=$ $1-17 \%)$ was similar between dyad types $\left(F_{2,75}=0.97, P=\right.$ $0.33)$. Pasture habitat and anthropogenic water sources were common attributes in core area OZs. All overlapping core areas encompassed $\geq 1$ water source and 64 included pastures being used by cattle.

Despite some consistency in variables retained in the best models of resource selection, there were important differences in the use of habitat types relative to sex and scale (Table 1). Probability of occurrence by male raccoons within $95 \%$ FK home ranges decreased closer to roads $(\beta=0.001)$ and increased in mixed forest $(\beta=0.813)$, wetlands $(\beta=$ $0.415)$, and closer to water $(\beta=-0.001)$. In $50 \%$ FK core areas, probability of occurrence by males increased in mixed forest $(\beta=0.732)$, conifer $(\beta=0.504)$, and closer to water $(\beta=-0.001)$ and decreased closer to roads $(\beta=0.001)$. Probability of occurrence by males in OZs increased at anthropogenic features $(\beta=2.546)$, in mixed forest $(\beta=$ $0.513)$, and closer to water $(\beta=-0.001)$ and decreased closer to roads $(\beta=0.002)$.

As with resource selection by males, there were some consistencies in variables retained in the best models of female resource selection, including retention of the same variables for top core area and OZ models. Probability of occurrence by female raccoons within $95 \%$ FK home ranges decreased closer to roads $(\beta=0.001)$ and in corn fields $(\beta=$ $-1.306)$ and increased in pasture $(\beta=0.413)$ and closer to water $(\beta=-0.001)$. In core areas, probability of occurrence by females increased in conifer $(\beta=0.676)$, pastures $(\beta=$ $0.477)$, and closer to water $(\beta=-0.001)$ and decreased closer to roads $(\beta=0.001)$. The top $\mathrm{OZ}$ model retained the same variables as the top core-area model; coefficients were qualitatively similar with the exception that probability of occurrence in OZs decreased in conifer $(\beta=-3.387)$. Because top core-area and $\mathrm{OZ}$ models contained the same variables, covariance-variance structures were identical and we could directly compare relative odds ratios between models. In direct comparison to core areas, females in OZs were 1.6 times more likely to use pastures, 3 times more likely to be located closer to water, 2 times less likely to be located closer to roads, and 4 times less likely use conifer patches (Table 1).

\section{Interaction}

Three variables were retained in our top model of factors correlated with probability of interaction for overlapping raccoon dyads. Probabilities of interaction were negatively 
Table 1. Relative odds ratios of parameter estimates, standard errors, $P$-values, and corresponding $95 \%$ confidence intervals for independent variables in resource selection function models for the best Akaike's Information Criterion ( $\mathrm{AIC}_{i}$; corrected for small sample size) male and female raccoon $95 \%$ fixed kernel (FK; home range), 50\% FK (core area), and overlap zone (OZ) models, Alcona County, northeastern Michigan, USA, 2004.

\begin{tabular}{|c|c|c|c|c|c|c|c|c|}
\hline Model & Conifer & Mixed forest & Wetland & Pasture & Anthropogenic & Corn field & Distance road & Distance water \\
\hline M 95\% FK & & 1.413 & 1.366 & & & & 0.998 & 1.0008 \\
\hline SE & & 0.129 & 0.221 & & & & 0.0001 & 0.0001 \\
\hline$P$-value & & $<0.0001$ & 0.041 & & & & $<0.0001$ & 0.014 \\
\hline $95 \% \mathrm{CI}$ & & $0.367-0.5861 .005-2.340$ & & & & $0.994-1.006$ & $0.992-1.013$ & \\
\hline F $95 \%$ & & & & 1.277 & & 0.318 & 0.999 & 0.999 \\
\hline SE & & & & 0.143 & & 0.405 & 0.0002 & 0.0001 \\
\hline$P$-value & & & & 0.029 & & 0.009 & $<0.0001$ & $<0.0001$ \\
\hline $95 \% \mathrm{CI}$ & & & & $1.026-1.860$ & & $0.155-0.791$ & $0.990-1.009$ & 0.993-1.010 \\
\hline M 50\% & 1.701 & 1.423 & & & & & 0.999 & 0.999 \\
\hline SE & 0.226 & 0.143 & & & & & 0.0002 & 0.0001 \\
\hline$P$-value & 0.021 & $<0.0001$ & & & & & $<0.0001$ & 0.005 \\
\hline $95 \% \mathrm{CI}$ & $1.066-2.462$ & $0.320-0.560$ & & & & & $0.996-1.004$ & $0.992-1.008$ \\
\hline F $50 \%$ & 2.242 & & & 1.721 & & & 0.999 & 0.998 \\
\hline $\mathrm{SE}$ & 0.265 & & & 0.146 & & & 0.0002 & 0.0001 \\
\hline$P$-value & 0.002 & & & $<0.0001$ & & & $<0.0001$ & $<0.0001$ \\
\hline $95 \%$ CI & $1.339-3.717$ & & & $1.356-2.439$ & & & $0.996-1.003$ & 0.994-1.009 \\
\hline M OZ & & 1.381 & & & 2.078 & & 0.999 & 0.997 \\
\hline SE & & 0.157 & & & 1.051 & & 0.0002 & 0.0001 \\
\hline$P$-value & & $<0.0001$ & & & 0.016 & & $<0.0001$ & 0.019 \\
\hline $95 \% \mathrm{CI}$ & & $1.218-1.580$ & & & $2.009-2.666$ & & $0.997-1.001$ & $0.995-0.999$ \\
\hline $\mathrm{F} \mathrm{OZ}$ & -3.387 & & & 2.492 & & & 0.998 & 0.996 \\
\hline SE & 1.045 & & & 0.186 & & & 0.0003 & 0.0003 \\
\hline$P$-value & 0.001 & & & $<0.0001$ & & & $<0.0001$ & $<0.0001$ \\
\hline $95 \% \mathrm{CI}$ & $-3.834-0.262$ & & & $1.730-3.590$ & & & $0.997-0.999$ & 0.994-1.0001 \\
\hline
\end{tabular}

correlated with MSD of nearest-neighbor distance between mixed forest $(\beta=-0.638, \mathrm{SE}=0.084)$, wetlands $(\beta=$ $-0.207, \mathrm{SE}=0.045)$, and dyad type $(\beta=-0.068, \mathrm{SE}=$ 0.026). That is, probability of interaction increased with decreasing distance between nearest-neighbor mixed forest and wetland habitat patches. Furthermore, probabilities of interaction were similar for adjacent male-male $(n=59, \bar{x}=$ $0.38, \mathrm{SE}=0.04,95 \% \mathrm{CI}=0.31-0.46)$ and male-female $(n$ $=18, \bar{x}=0.40, \mathrm{SE}=0.05,95 \% \mathrm{CI}=0.30-0.50)$ dyads, both of which were substantially greater than female-female dyads $(n=11, \bar{x}=0.09, \mathrm{SE}=0.03,95 \% \mathrm{CI}=0.03-0.15)$. Although the top model captured a substantial portion of variation $\left(R^{2}=0.61\right)$, partial regressions indicated that most of the variation could be attributed to the nearest-neighbor distance between mixed forest $\left(r^{2}=0.49\right)$, followed by nearest-neighbor distance between water features $\left(r^{2}=0.09\right)$ and dyad type $\left(r^{2}=0.03\right)$. The top-ranked model was only approximately 1.6 times as likely to be the best candidate as the second-ranked model (NN indicates nearest neighbor): $\beta_{0}-\beta_{1}(\mathrm{NN}$ wetland $)-\beta_{2}(\mathrm{NN}$ mixed forest $)-\beta_{3}(\mathrm{NN}$ pasture $)-\beta_{4}($ dyad type), and the inclusion of pasture habitat in the second-ranked model failed to raise the $R^{2}$ value (Table 2). However, the top-ranked and secondranked models were 7.4 and 4.5 times, respectively, better candidates than the third-ranked model (Table 2). Despite uncertainty relative to the top 2 models, the retention of nearest-neighbor distances between mixed forest and wetland patches supports their importance to probabilities of interaction.

Using data loggers and infrared cameras, we documented 284 visitations to water sources by 12 radiocollared raccoons ( $n=218$ visits) and the 9 radiocollared cows ( $n=66$ visits) over 91 camera-nights. Duration of water visitation was greater $(H=9.0, \mathrm{df}=1, P=0.01)$ for raccoons $(\bar{x}=27.6$ $\min , 95 \% \mathrm{CI}=15.7-39.4)$ than cows $(\bar{x}=2.0 \mathrm{~min}, 95 \% \mathrm{CI}$ $=0.5-3.4)$. Although raccoons and cows shared water, they partitioned use temporally. Ninety-seven percent of raccoon visitations occurred nocturnally (i.e., 2000-0500 hr) and temporal spacing between raccoon and cow visits averaged 7 hours $(\mathrm{SE}=0.87 \mathrm{hr})$. We also used infrared cameras to

Table 2. Model structure, $R$-square $\left(R^{2}\right)$, corresponding Akaike's Information Criterion ( $\mathrm{AIC}_{c}$; adjusted for small sample size), and Akaike weight $\left(w_{i}\right.$; Burnham and Anderson 2002) for the top 4 models of interaction probabilities $\left(P_{i j}\right)$ for spatially overlapping raccoon dyads in Alcona County, northeastern Michigan, USA, 2004.

\begin{tabular}{|c|c|c|c|}
\hline Model structure $^{\mathrm{a}}$ & $R^{2}$ & $\mathrm{AIC}_{c}$ & $w_{i}$ \\
\hline 1. $\beta_{0}-\beta_{1}(\mathrm{MSD}$ mixed forest $)-\beta_{2}(\mathrm{MSD}$ wetland $)-\beta_{3}($ dyad type $)$ & 0.61 & -297.85 & 0.560 \\
\hline 2. $\beta_{0}-\beta_{1}(\mathrm{MSD}$ mixed forest $)-\beta_{2}(\mathrm{MSD}$ wetland $)-\beta_{3}$ (dyad type $)-\beta_{4}(\mathrm{MSD}$ pasture $)$ & 0.61 & -295.76 & 0.338 \\
\hline 3. $\beta_{0}-\beta_{1}$ (MSD mixed forest) $-\beta_{2}$ (MSD wetland) & 0.58 & -294.93 & 0.075 \\
\hline 4. $\beta_{0}-\beta_{1}$ (MSD mixed forest $)-\beta_{2}$ (MSD wetland $)-\beta_{3}($ MSD pasture $)$ & 0.58 & -291.85 & 0.028 \\
\hline 5. $\beta_{0}-\beta_{1}(\mathrm{MSD}$ mixed forest $)-\beta_{2}($ dyad type $)$ & 0.51 & -281.93 & 0.0001 \\
\hline
\end{tabular}

${ }^{\mathrm{a}} \mathrm{MSD}=$ mean squared differences. 
document raccoons consuming cattle feed in troughs, granaries, and hay storage facilities on 41 separate occasions over 52 camera-nights.

\section{DISCUSSION}

We documented the potential for spatial interaction between raccoons and domestic livestock exploiting shared resources during spring and summer. The extent of interaction was strongly influenced by raccoon social organization and spatial ecology, along with the sedentary nature of cattle confined to small scale (e.g., $<150$ ha) livestock operations. In the case of large operations, the extent of raccoon-cattle interaction should be more or equally dependent upon the presence of cattle, which is more easily managed. However, for modest operations such as the ones we monitored, where farms occupied nearly the same area $(\bar{x}=131 \mathrm{ha})$ as raccoon home ranges $\left(1.51 \mathrm{~km}^{2}\right)$, it would be more difficult to reduce probability of interaction by managing cattle distribution in pastures. Indeed, the raccoon-livestock spatial interactions we observed were not restricted to natural habitats (e.g., pasture, forest), but also occurred at livestock water and feed sources. Our results highlight the potential for transmission of bTB between wildlife, livestock, and humans at small-scale livestock operations.

Intersexual differences in raccoon resource selection during the growing season have been attributed to additional resource needs of females with dependent young (Fritzell 1978, Endres and Smith 1993). We believe selection of pasture habitat by females reflects attempts to meet those additional needs. In agro-ecosystems pasture habitat can be a good source of insects and eggs from avian nests (Beasley et al. 2007), both of which are high in protein and important food sources for developing young. Moreover, feeding troughs that occasionally contained supplemental feed (i.e., corn, minerals) were common features in pastures and represented an anthropogenic food source that female raccoons could exploit while not competing with males for food in barns and silos. Selection of conifer patches at the core-area scale likely reflects the need for females to provide protective shelter for dependent young (Gehrt and Fritzell 1998).

The OZ concentrates resource exploitation between adjacent individuals in a small area and because of this, potential for agonistic interaction between overlapping individuals can be elevated (Atwood and Weeks 2003, Atwood et al. 2007). Moreover, when OZs are configured around resource rich patches such as pastures or livestock feeding or husbandry facilities, there can be an increased likelihood of pathogen acquisition through agonism resulting from scramble competition for food (Clifton-Hadley et al. 1993). Because of the importance of focal attractors in mediating pathogen transmission (Atwood et al. 2007), it is necessary to confirm that patches function as such within OZs so that subsequent management actions are properly targeted. For male raccoons, we confirmed anthropogenic features and mixed-forest patches as focal attractors in OZs by comparing patch selection between core area and $\mathrm{OZ}$ scales. A similar approach was not possible for females because top RSF models for core areas and OZs retained the same variables. However, retention of consistent sets of RSF parameters and the resultant consistent covariance matrices allowed us to directly compare coefficients (Hosmer and Lemeshow 2000) from female core areas and OZs and, thereby, assess the relative importance of those parameters based on scale. Thus, although retention of patch types in top RSFs was similar, intensity of exploitation differed substantially. For OZs, probability of female occurrence in pasture patches was 1.6 times greater, whereas probability of occurrence in conifer patches was substantially less than occurrence in core areas. This would indicate that unlike males, females were not attracted to different habitat types within OZs but rather varied the intensity of patch exploitation at finer scales.

It is important to note that, based on our sampling design, we could quantify spatial rather than temporal interaction. Simultaneous use of resources should increase the potential for temporal interaction and, thus, pathogen transmission. However, we feel that for raccoons and cattle, pathogen transmission also is likely to occur through indirect means, such as consumption of infected feed or water. As with resource selection, probabilities of interaction were strongly influenced by sex and landscape composition, so it is important to conceptualize sex and landscape composition working synergistically to influence transmission potential. The former suggests a sex-bias in the potential vectoring of disease to and from livestock, whereas the latter indicates patch juxtaposition can function to facilitate horizontal pathogen transmission (Atwood et al. 2007) between raccoons and livestock.

Probabilities of interaction for male-male and malefemale dyads were greater than for female-female dyads, and partial regressions support this sex-bias by indicating that the distance between nearest-neighbor mixed-forest patches accounted for a preponderance of the variation. Mixedforest patches were important to males at all observed spatial scales and, within OZs, we believe they served as travel corridors to access food-rich anthropogenic features and provided protective cover that facilitated spatial tolerance of conspecifics. The importance of forested habitat to raccoons has been reported in other studies and is most often attributed to providing access to primary food resources and den sites (e.g., Pedlar et al. 1997, Chamberlain et al. 2002, Beasley et al. 2007). Male raccoons are generally more gregarious than females (Gehrt and Fritzell 1998), and we believe that, in fragmented landscapes, forest patches juxtaposed with anthropogenic features greatly facilitates spatial interaction between males. The role of habitat patch juxtaposition in mediating social structure in mesocarnivores inhabiting fragmented landscapes remains a relatively unexplored facet of carnivore ecology and warrants further investigation.

The potential for adverse health ramifications of use of livestock husbandry and feeding facilities by raccoons, 
particularly where bTB is concerned is high. Clinical symptoms of bTB are not manifest until the disease has reached an advanced stage (Cheeseman and Mallinson 1981, Garnett et al. 2005), at which point attempts at prophylaxis are ineffective (Francis 1958, deLisle et al. 2002). Our remote surveillance efforts at artificial water sources and livestock production facilities suggest that shared primary resources of food and water may function as a mechanism that can mediate pathogen transmission between raccoons and livestock. Transmission of bTB primarily occurs through inhalation of aerosolized bacilli or ingestion of infected material (Francis 1958); within semi-closed structures such as livestock feeding facilities (i.e., loafing or feeding sheds), dispersion of aerosolized bacilli is impeded and, thus, concentrated relative to open environments. Furthermore, because humans must frequent livestock production facilities as a primary function of animal husbandry, there is potential for humans to come into contact with concentrated pathogens indirectly via the raccoon-livestock transmission axis.

\section{MANAGEMENT IMPLICATIONS}

Our results indicate that raccoons are most likely to exploit anthropogenic features when they are located adjacent to mixed-forest patches. Thus, caution should be exercised in deciding placement of livestock feeding and watering facilities in BTB endemic areas when mixed-forest patches are adjacent. We recommend locating livestock facilities within the $\mathrm{bTB}$ endemic zone $>1 \mathrm{~km}$ from mixed-forest patches. Of course, it is essential that rigorous animal husbandry practices, such as ensuring silage and other feed are not readily accessible, supplemental feed is not placed on the ground in pastures, feed troughs are inspected for contamination by wildlife, and perimeter fencing is adequate to prevent nose-to-nose contact between neighboring herds, be maintained regardless of how far facilities are from forest patches. We emphasize that we are not discounting the importance of social interaction in mediating pathogen acquisition. Rather, we feel it may be more practical to mitigate future outbreaks of bTB in endemic areas by altering the placement of livestock feeding and watering features as opposed to disrupting heritable social behaviors.

\section{ACKNOWLEDGMENTS}

D. Baasch, T. Messmer, R. Baldwin, and an anonymous reviewer provided helpful comments on an earlier version of this manuscript.

\section{LITERATURE CITED}

Arthur, S. M., B. F. J. Manly, L. L. McDonald, and G. W. Garner. 1996. Assessing habitat selection when availability changes. Ecology 77:215227.

Atwood, T. C., K. C. VerCauteren, T. J. DeLiberto, H. J. Smith, and J. S. Stevenson. 2007. Coyotes as sentinels for monitoring bovine tuberculosis prevalence in white-tailed deer. Journal of Wildlife Management 71: $1545-1554$.

Atwood, T. C., and H. P. Weeks, Jr. 2003. Spatial home-range overlap and temporal interaction in eastern coyotes: the influence of pair types and fragmentation. Canadian Journal of Zoology 81:1589-1597.
Beasley, J. C., T. L. DeVault, M. I. Retamosa, and O. E. Rhodes, Jr. 2007. A hierarchical analysis of habitat selection by raccoons in Northern Indiana. Journal of Wildlife Management 71:1125-1133.

Berentsen, A. R., M. R. Dunbar, and R. G. McLean. 2007. Research strategies of the National Wildlife Research Center to control bovine tuberculosis in wildlife in Michigan, USA. Pages 174-177 in G. Wibbelt, N. Bergholz, S. Seet, and H. Hofer, editors. Erkrankungen der Zootiere I Verhandlungsbericht des 43. Internationalen Symposiums iiber die Erkrankungen der Zoo- und Wildtiere. Institut fiir Wild- und Zootierforschung im Forschungsverbund, Berlin, Germany. [In English.]

Blancou, J., B. B. Chomel, A. Belotto, and F. X. Meslin. 2005. Emerging or reemerging bacterial zoonoses: factors of emergence, surveillance, and control. Veterinary Research 36:507-522.

Broadfoot, J. D., R. C. Rosatte, and D. T. O'Leary. 2001. Raccoon and skunk population models for urban disease control planning in Ontario, Canada. Ecological Applications 11:295-303.

Burnham, K. P., and D. R. Anderson. 2002. Model selection and multimodel inference: a practical information-theoretic approach. Second edition. Springer-Verlag, New York, New York, USA.

Chamberlain, M. J., L. M. Conner, and B. D. Leopold. 2002. Seasonal habitat selection by raccoons (Procyon lotor) in intensively managed pine forests of central Mississippi. American Midland Naturalist 147:102-108.

Cheeseman, C. L., and P. J. Mallinson. 1981. Behavior of badgers (Meles meles) infected with bovine tuberculosis. Journal of Zoology, London 197: 289-292.

Cleaveland, S., M. K. Laurenson, and L. H. Taylor. 2001. Diseases of humans and their domestic mammals: pathogen characteristics, host range and the risk of emergence. Philosophical Transactions of the Royal Society of London, B 356:991-999.

Clifton-Hadley, R. S., J. W. Wilesmith, and F. A. Stuart. 1993 Mycobacterium bovis in the European badger (Meles meles): epidemiological findings in tuberculous badgers from a naturally infected population. Epidemiology and Infection 111:9-19.

Conner, M. M., and M. W. Miller. 2004. Movement patterns and spatial epidemiology of a prion disease in mule deer population units. Ecological Applications 14:1870-1881.

Crooks, K., and M. E. Soule. 1999. Mesopredator release and avifaunal extinctions in a fragmented system. Nature 400:563-566.

de Lisle, G. W., R. G. Bengis, S. M. Schmitt, and D. J. O'Brien. 2002. Tuberculosis in free-ranging wildlife: detection, diagnosis, and management. Scientific and Technical Review of the Office of International des Epizooties 21:317-334.

Dobson, A. P., and J. Foufopoulos. 2001. Emerging infectious pathogens of wildlife. Philosophical Transactions of the Royal Society of London, B 356:1001-1012.

Endres, K. M., and W. P. Smith. 1993. Influence of age, sex, season, and availability on den selection by raccoons in the central basin of Tennessee. American Midland Naturalist 129:116-131.

Francis, J. 1958. Tuberculosis in animals and man. Cassell, London, United Kingdom.

Fritzell, E. K. 1978. Habitat use by prairie raccoons during the waterfowl breeding season. Journal of Wildlife Management 42:118-127.

Garnett, B. T., R. J. Delahay, and T. J. Roper. 2005. Ranging behaviour of European badgers (Meles meles) in relation to bovine (Mycobacterium bovis) tuberculosis infection. Applied Animal Behaviour Science 94:331340.

Gehrt, S. D., and E. K. Fritzell. 1998. Resource distribution, female home range dispersion and male spatial interactions: group structure in a solitary carnivore. Animal Behaviour 55:1211-1227.

Hess, G. R., S. E. Randolph, P. Arneberg, C. Chemimi, C. Furlanello, J. Harwood, M. G. Roberts, and J. Swinton. 2002. Spatial aspects of disease dynamics. Pages 102-118 in P. J. Hudson, A. Rizzoli, B. T. Grenfell, H. Heesterbeek, and A. P. Dobson, editors. The ecology of wildlife diseases. Oxford University Press, Oxford, United Kingdom.

Hosmer, D. W., and S. Lemeshow. 2000. Applied logistic regression. John Wiley \& Sons, Hoboken, New Jersey, USA.

Isbell, L. A., J. D. Pruetz, and T. P. Young. 1998. Movements of vervets (Cercopithecus aethiops) and patas (Erythrocebus patas) monkeys as estimators of food resource size, density, and distribution. Behavioral Ecology and Sociobiology 42:123-133.

Johnson, C. J., S. E. Nielsen, E. H. Merrill, T. L. McDonald, and M. S. Boyce. 2006. Resource selection functions based on use-availability data: 
theoretical motivation and evaluation methods. Journal of Wildlife Management 70:347-357.

Lee, J. E., G. C. White, R. A. Garrott, R. M. Bartmann, and A. W. Allredge. 1985. Assessing the accuracy of a radiotelemetry system for estimating mule deer locations. Journal of Wildlife Management 49:658663.

Macdonald, D. W., O. Courtenay, S. Forbes, and F. Mathews. 1999. The red fox (Vulpes vulpes) in Saudi Arabia: loose knit groupings in the absence of territoriality. Journal of Zoology, London 249:383-391.

Manly, B. F. J., L. L. McDonald, D. L. Thomas, L. L. McDonald, and W. P. Erickson. 2002. Resource selection by animals: statistical design and analysis for field studies. Kluwer Academic, Norwell, Massachusetts, USA.

McCallum, H., and A. P. Dobson. 2002. Disease, habitat fragmentation, and conservation. Proceedings of the Royal Society B: Biological Sciences 269:2041-2049.

Michigan Department of Natural Resources. 2005. Michigan bovine tuberculosis eradication project: activities report and conference proceedings. Michigan Department of Natural Resources, East Lansing, USA.

Mollison, D., and S. A. Levin. 1995. Spatial dynamics of parasitism. Pages 384-398 in A. P. Dobson and B. Grenfell, editors. Ecology of infectious diseases in natural populations. Cambridge University Press, Cambridge, United Kingdom.

Nams, V. O. 1990. Locate II user's guide. Pacer Computer Software, Truro, Nova Scotia, Canada.

Neter, J., M. H. Kutner, C. J. Nachtsheim, and W. Wasserman. 1996. Applied linear statistical models. McGraw-Hill, Boston, Massachusetts, USA.

Pedlar, J. H., L. Fahrig, and H. G. Merriam. 1997. Raccoon habitat use at 2 spatial scales. Journal of Wildlife Management 61:102-112.

Prange, S., S. D. Gehrt, and E. P. Wiggers. 2004. Influences of anthropogenic resources on raccoon (Procyon lotor) movements and spatial distribution. Journal of Mammalogy 85:483-490.

Rhodes, C. J., R. P. D. Atkinson, R. M. Anderson, and D. W. Macdonald. 1998. Rabies in Zimbabwe: reservoir dogs and the implications for disease control. Philosophical Transactions of the Royal Society of London, Series B 353:999-1010.

Roussere, G. P., W. J. Murray, C. B. Raudenbush, M. J. Kutileck, D. J. Levee, and K. R. Kazacos. 2002. Raccoon roundworm eggs near homes and risk for Larva migrans disease, California communities. Emerging Infectious Disease 9:1516-1522.

Sawyer, H., R. M. Nielson, F. Lindzey, and L. L. McDonald. 2006. Winter habitat selection by mule deer before and during development of a natural gas field. Journal of Wildlife Management 70:396-403.
Schmitt, S. M., S. D. Fitzgerald, T. M. Cooley, C. S. Bruning-Fann, L. Sullivan, D. Berry, T. Carlson, R. B. Minnis, J. B. Payeur, and J. Sikarskie. 1997. Bovine tuberculosis in free-ranging white-tailed deer in Michigan. Journal of Wildlife Diseases 33:749-758.

Schrag, S. J., and P. Wiener. 1995. Emerging infectious disease: what are the relative roles of ecology and evolution? Trends in Ecology and Evolution 10:319-324.

Seaman, D. E., J. J. Millspaugh, B. J. Kernohan, G. C. Brundige, K. J. Raedeke, and R. A. Gitzen. 1999. Effects of sample size on kernel home range estimates. Journal of Wildlife Management 63:739-747.

Smith, D. L., B. Lucey, L. A. Waller, J. E. Childs, and L. A. Real. 2002. Predicting the spatial dynamics of rabies epidemics on heterogeneous landscapes. Proceedings of the National Academy of Science 99:36683672.

Swihart, R. K., and N. A. Slade. 1997. On testing for independence of animal movements. Journal of Agricultural, Biological, and Environmental Statistics 2:48-63.

Taylor, L. H., S. Latham, and M. E. J. Woolhouse. 2001. Risk factors for human disease emergence. Philosophical Transactions of the Royal Society of London, Series B 356:983-990.

Theobald, D. M. 2003. Targeting conservation action through assessment of protection and exurban threats. Conservation Biology 17:1624-1637.

Turner, M. G. 1989. Landscape ecology: the effect of pattern on process Annual Review of Ecology and Systematics 20:171-197.

Tuyttens, F. A. M., R. J. Delahay, D. W. Macdonald, C. L. Cheeseman, B. Long, and C. A. Donnelly. 2000. Spatial perturbation caused by a badger (Meles meles) culling operation: implications for the function of territoriality and the control of bovine tuberculosis (Mycobacterium bovis). Journal of Animal Ecology 69:815-828.

White, G. C., and R. A. Garrott. 1990. Analysis of wildlife radio-tracking data. Academic Press, New York, New York, USA.

Wiens, J. A., J. T. Rotenberry, and B. Vanhorne. 1986. A lesson in the limitations of field experiments: shrub-steppe birds and habitat alteration. Ecology 67:365-376.

Wilmhurst, J. F., J. M. Fryxell, B. P. Farm, A. R. E. Sinclair, and C. P. Henschel. 1999. Spatial distribution of Serengeti wildebeest in relation to resources. Canadian Journal of Zoology 77:1223-1232.

Woolhouse, M. E. J., and S. Gowtage-Sequeria. 2005. Host range and emerging and reemerging pathogens. Emerging Infectious Diseases 11: 1842-1847.

Zar, J. H. 1999. Biostastistical analysis. Fourth edition. Prentice Hall, Upper Saddle River, New Jersey, USA.

Associate Editor: Messmer. 